\title{
Giant aortic root aneurysm in Marfan syndrome: A rare complication in early childhood
}

\author{
Patrick O. Myers, MD, ${ }^{\mathrm{a}, \mathrm{b}}$ Yacine Aggoun, $\mathrm{MD},{ }^{\mathrm{c}}$ and Cecile Tissot, $\mathrm{MD}^{\mathrm{c}}$
}

\begin{abstract}
A 7-year-old girl presented with shortness of breath on exertion and palpitations. Features of Marfan syndrome were noted on physical examination. The chest x-ray revealed marked cardiomegaly with a widened mediastinum (Figure 1). Echocardiography showed a gigantic dilatation of the aortic root (Figure 2). The aortic valve annulus measured $3.7 \mathrm{~cm}(\mathrm{Z}$-score +12$)$, and the maximal diameter at the sinuses of Valsalva measured $8.7 \mathrm{~cm}$ (Z-score +14 ), with severe aortic regurgitation, left ventricular dilatation, and depressed left ventricular function. Cardiac magnetic resonance imaging was impressive for severe dilatation of the ascending aorta (Figure 3) comprising the annulus, sinuses of Valsalva, sinotubular junction, and tubular ascending aorta, with severe aortic regurgitation (regurgitant fraction, 44\%), severe left ventricular dilatation, and depressed systolic function (ejection fraction, $36 \%$ ). The child was brought to the operating room. Given the proximity of the giant aneurysm to the sternum, the child was placed on cardiopulmonary bypass by femoral vessel cannulation, and adequate drainage of the heart was confirmed before sternotomy. The aortic root and ascending aorta were replaced with a $28-\mathrm{mm}$ Gelweave Valsalva tube graft (Terumo Cardiovascular Systems Corporation, Ann Arbor, Mich) using the David valve-sparing root replacement operation, remodeling the annulus with multiple subannular sutures. Post-bypass echocardiography showed moderate aortic regurgitation and severe left ventricular dysfunction and dilatation. The reimplanted native valve had to be replaced with a Carpentier-Edwards Perimount Magna 21-mm bioprosthesis (Edwards Lifesciences LLC, Irvine, Calif) within the Valsalva graft. Because of severe left ventricular dysfunction, the child could not be
\end{abstract}

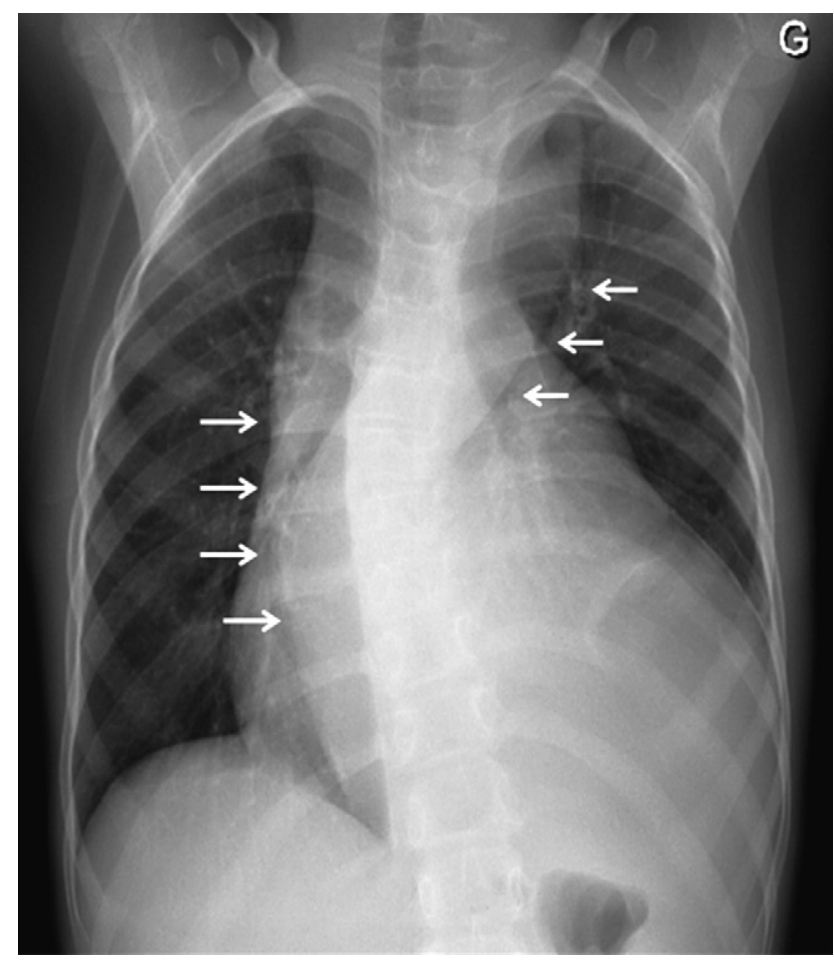

FIGURE 1. Chest $x$-ray demonstrating the aneurysmal dilation of the ascending aorta.

weaned from cardiopulmonary bypass and was placed on a left ventricular assist device.

The authors thank Dominique Didier, Department of Radiology, Geneva University Hospitals, Geneva, Switzerland, for assistance in preparing magnetic resonance images.

\footnotetext{
From the Department of Cardiac Surgery, ${ }^{\text {a }}$ Children's Hospital and Harvard Medical School, Boston, Mass; Division of Cardiovascular Surgery, ${ }^{\mathrm{b}}$ Geneva University Hospitals, Geneva, Switzerland; and Pediatric Cardiology Unit, ${ }^{\mathrm{c}}$ Children's University Hospital of Geneva, Switzerland

Disclosures: Authors have nothing to disclose with regard to commercial support.

Received for publication Aug 20, 2010; accepted for publication Aug 24, 2010.

Address for reprints: Cecile Tissot, MD, Pediatric Cardiology Unit, The University

Children's Hospital of Geneva, 6, rue Willy Donze, 1211 Geneva 14, Switzerland

(E-mail: cecile.tissot@hotmail.com).

J Thorac Cardiovasc Surg 2011;141:293-4

$0022-5223 / \$ 36.00$

Copyright (C) 2011 by The American Association for Thoracic Surgery

doi:10.1016/j.jtcvs.2010.08.076
} 

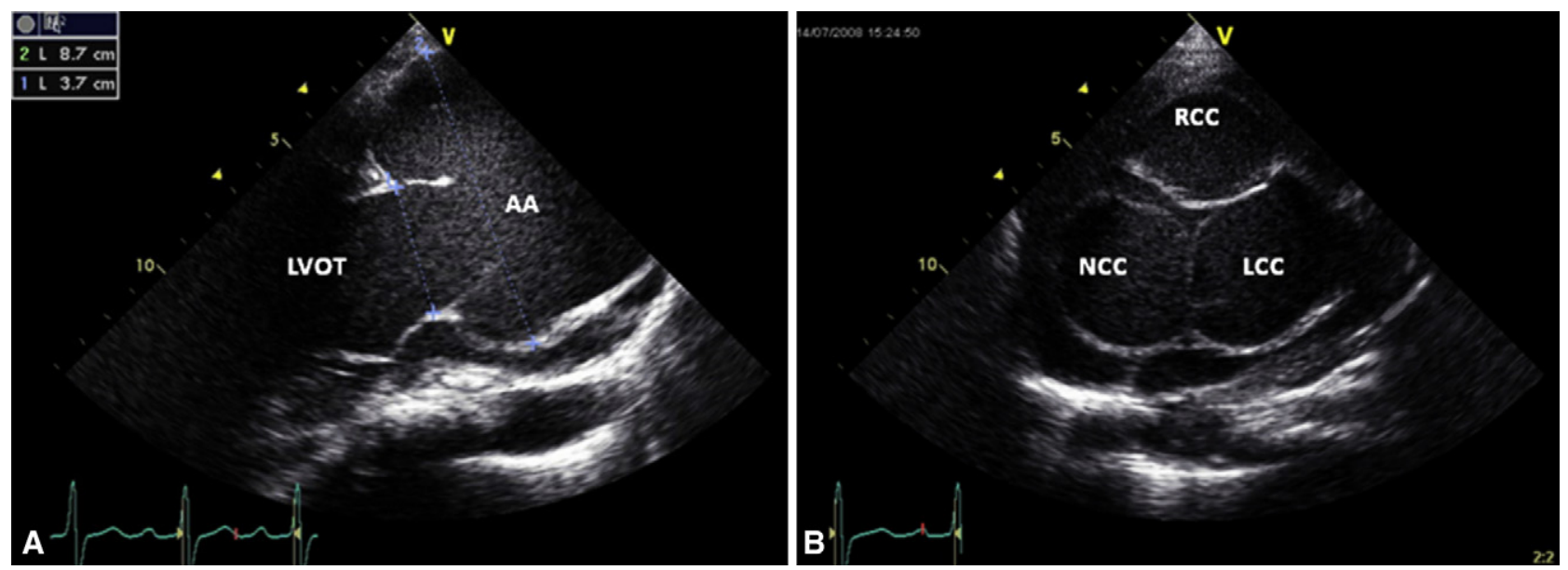

FIGURE 2. Echocardiography long-axis view (A) demonstrating a large ascending aortic aneurysm with aortic root dilation (aortic valve annulus, $3.7 \mathrm{~cm}$; Z-score +12 ; sinuses of Valsalva, $8.7 \mathrm{~cm}$; Z-score +14 ) and short-axis view (B) at the level of the base with non-coaptation of the right and noncoronary cusps responsible for severe aortic valve insufficiency. $A A$, Ascending aorta; $L C C$, left coronary cusp; $L V$, left ventricle; $L V O T$, left ventricle outflow tract; $N C C$, noncoronary cusp; $R C C$, right coronary cusp.

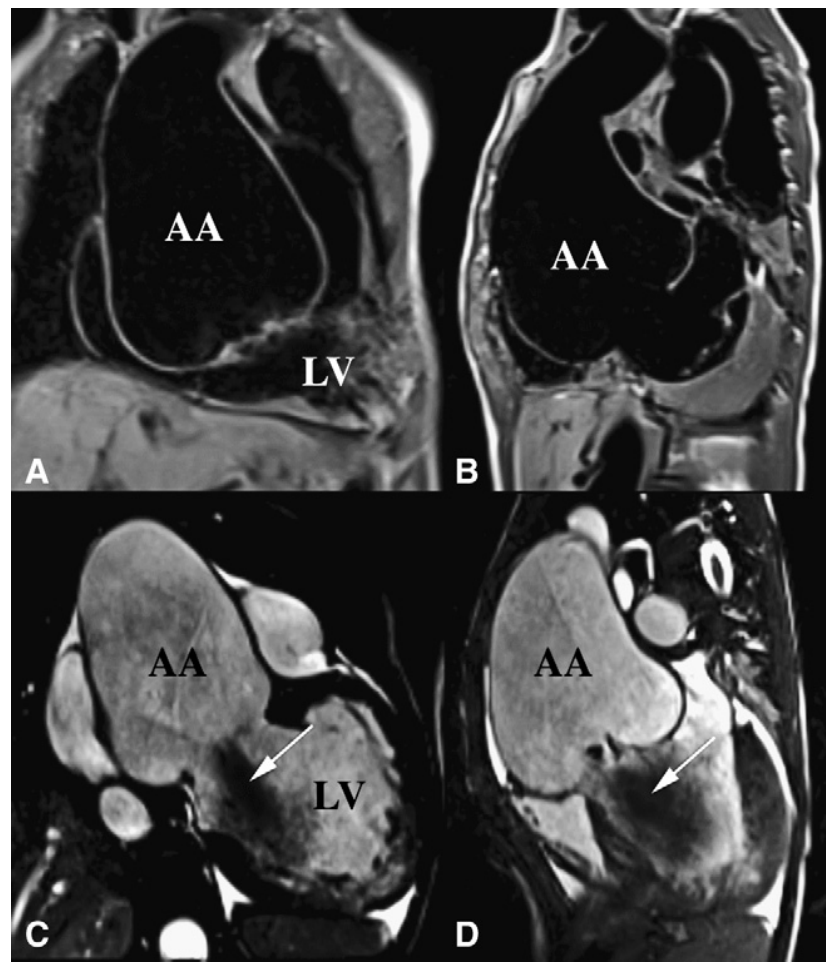

FIGURE 3. Cardiac magnetic resonance imaging: Coronal (A) and oblique sagittal (B) views showing severe annuloaortic ectasia on spin-echo images. Cine images in the same planes $(C, D)$ demonstrating a large flow void in diastole (arrows) corresponding to a severe aortic regurgitation. $A A$, Ascending aorta; $L V$, left ventricle. 